\title{
Solution of the Boundary Layer Equation of the Power-Law Pseudoplastic Fluid Using Differential Transform Method
}

\author{
Sobhan Mosayebidorcheh \\ Department of Mechanical Engineering, Islamic Azad University, Najafabad Branch, Isfahan, Iran \\ Correspondence should be addressed to Sobhan Mosayebidorcheh; sobhan_phd@yahoo.com
}

Received 26 July 2013; Revised 26 September 2013; Accepted 22 October 2013

Academic Editor: Metin O. Kaya

Copyright ( 2013 Sobhan Mosayebidorcheh. This is an open access article distributed under the Creative Commons Attribution License, which permits unrestricted use, distribution, and reproduction in any medium, provided the original work is properly cited.

The boundary layer equation of the pseudoplastic fluid over a flat plate is considered. This equation is a boundary value problem (BVP) with the high nonlinearity and a boundary condition at infinity. To solve such problems, powerful numerical techniques are usually used. Here, through using differential transform method (DTM), the BVP is replaced by two initial value problems (IVP) and then multi-step differential transform method (MDTM) is applied to solve them. The differential equation and its boundary conditions are transformed to a set of algebraic equations, and the Taylor series of solution is calculated in every sub domain. In this solution, there is no need for restrictive assumptions or linearization. Finally, DTM results are compared with the numerical solution of the problem, and a good accuracy of the proposed method is observed.

\section{Introduction}

Boundary layer equation of the Newtonian fluid over a flat plate is one of the classic issues of mechanical engineering. Because of high level of application of non-Newtonian fluids in industry, the boundary layer equation of the nonNewtonian fluids is being noted by engineers. On the other hand, nonlinearity of these equations attracted the interest of mathematicians to evaluate the power and accuracy of the approximate and numerical methods. One of the most significant non Newtonian models is the power law one. In this model, shear thinning or shear thickening property of the fluid is considered and the shear stress has a nonlinear relation with shear rate, while shear stress has a linear relation with shear rate for the Newtonian fluid.

As we pointed out above, boundary layer problems are among the nonlinear ones and most of them do not have an exact analytical solution. So, numerical and approximate methods are used by researchers to solve such equations. The most known numerical method used to solve boundary layer problems is the shooting one. Based on this method, boundary value problem is transformed to an initial value problem with unknown initial values. After that, the problem is replaced with a system of first-order ordinary differential equations and usually is solved through Runge-Kutta method. Shooting method is appropriate to solve many boundary value problems, but this one is not useful for solving some BVPs because of the instability of the solution.

Approximate techniques like decomposition method (DM), homotopy analysis method (HAM), homotopy perturbation method (HPM), and variational iteration method (VIM) are good substitutes for numerical methods. During the recent years, boundary layer problems have been solved using some of these methods, such as HAM [1-9], HPM [10-14], VIM [15-17], and DM [18-21]. In most of the researches, some modifications were introduced to overcome the nonlinearity and the boundary condition at infinity.

Differential transform method (DTM) is also one of the other approximate methods to solve differential equations. Here, DTM and multi-step DTM are used to solve the boundary layer equation of the pseudoplastic fluid. This method was introduced by Zhou [22] to solve initial value problems in analysis of the electrical circuits. After that, DTM is applied to differential algebraic equation $[23,24]$, partial differential equation [25-30], integral equation [3133], ordinary differential equation [34-38], and fractional 
TABLE 1: The properties of the DTM and multi-step DTM.

\begin{tabular}{lcr}
\hline Original function & DTM & Multi-step DTM \\
\hline$f(t)=g(t) \pm s(t)$ & $F(k)=G(k) \pm S(k)$ & $F(k)=G(k) \pm S(k)$ \\
$f(t)=c g(t)$ & $F(k)=c G(k)$ & $F(k)=c G(k)$ \\
$\mathbf{f}(\mathbf{t})=\frac{\mathbf{d}^{\mathbf{n}} \mathbf{g}(\mathbf{t})}{\mathbf{d t}^{\mathbf{n}}}$ & $\mathbf{F}(\mathbf{k})=\frac{(\mathbf{k}+\mathbf{n}) !}{\mathbf{k} !} \mathbf{G}(\mathbf{k}+\mathbf{n})$ & $\mathbf{F}(\mathbf{k})=\frac{(\mathbf{k}+\mathbf{n}) !}{\mathbf{H}^{\mathbf{n}} \mathbf{k} !} \mathbf{G}(\mathbf{k}+\mathbf{n})$ \\
$f(t)=g(t) s(t)$ & $F(k)=\sum_{r=0}^{k} G(r) S(k-r)$ & $F(k)=\sum_{r=0}^{k} G(r) S(k-r)$ \\
\hline
\end{tabular}

differential equation [39-42]. The method is an iterative technique to find the Taylor series solution of the problem. There is no need for the high calculation cost to determine the coefficients of Taylor series, which is the reverse of the standard Taylor series method.

This paper is organized as follows. In Section 2, DTM and multi-step DTM are introduced. In Section 3, the boundary layer equation of the pseudoplastic fluid is extracted from continuity and momentum equations as presented in [43]. In Section 4 , the problem is solved and the results are illustrated as some figures and tables.

\section{Differential Transform Method}

The differential transform is defined as follows:

$$
X(k)=\frac{1}{k !}\left[\frac{d^{k} x(t)}{d t^{k}}\right]_{t=t_{0}},
$$

where $x(t)$ is an arbitrary function and $X(k)$ is the transformed function. The inverse transformation is as follows:

$$
x(t)=\sum_{k=0}^{\infty} X(k)\left(t-t_{0}\right)^{k} .
$$

Substituting (1) into (2), we have

$$
x(t)=\sum_{k=0}^{\infty} \frac{\left(t-t_{0}\right)^{k}}{k !}\left[\frac{d^{k} x(t)}{d t^{k}}\right]_{t=t_{0}} .
$$

The function $x(t)$ is usually considered as a series with limited terms and (2) can be rewritten as

$$
x(t) \approx \sum_{k=0}^{m} X(k)\left(t-t_{0}\right)^{k},
$$

where $m$ represents the number of Taylor series' components. Usually, through elevating this value, we can increase the accuracy of the solution.

Although the DTM series solution is a good approximate of the exact solution, but this series is diverged for greater areas. There are two ways to overcome this problem. One is the using pade approximate technique. Usually, Pade approximate gives us more exact information about the behavior of the solution (see [44]). Another one is to use multi-step DTM. Based on this one, solution domain is divided to some sub domains.

To solve a differential equation in the domain $[0, T]$ using multi-step DTM, this domain is divided to $N$ sections. We suppose the sub domains are equal and length of each sub domain is $H=T / N$. So, there is a separate function for every sub domain as follows:

$$
x(t)=\left\{\begin{array}{cl}
x_{1}(t), & t \in\left[t_{1}, t_{2}\right] \\
\vdots & \\
x_{i}(t), & t \in\left[t_{i}, t_{i+1}\right] \\
\vdots & \\
x_{N}(t), & t \in\left[t_{N}, t_{N+1}\right]
\end{array}\right.
$$

where $t_{i}=(i-1) H$. Multi-step DTM for every sub domain is defined as

$$
X_{i}(k)=\frac{H^{k}}{k !}\left[\frac{d^{k} x_{i}(t)}{d t^{k}}\right]_{t=t_{i}} .
$$

The inverse multi-step DTM is

$$
x_{i}(t)=\sum_{k=0}^{\infty} X_{i}(k)\left(\frac{t-t_{i}}{H}\right)^{k} .
$$

Some of the properties of DTM and multi-step DTM are shown in Table 1. These properties are extracted from (1) and (6).

\section{Mathematical Formulation}

Two-dimensional boundary layer equations for an incompressible fluid are

$$
\begin{gathered}
U \frac{\partial U}{\partial X}+V \frac{\partial U}{\partial Y}=\frac{1}{\rho} \frac{\partial \tau}{\partial Y} \\
\frac{\partial U}{\partial X}+\frac{\partial V}{\partial Y}=0
\end{gathered}
$$

where $\rho$ is the fluid density, $\tau$ is the shear stress, and $U$ and $V$ are the velocities in direction of $x$ and $y$, respectively. For the non-Newtonian power-law fluid, the shear stress is calculated through the following relation:

$$
\tau=m\left|\frac{\partial U}{\partial Y}\right|^{n-1} \frac{\partial U}{\partial Y}
$$

where $m$ and $n$ are the flow consistency and power-law index, respectively. 
Here, the following dimensionless parameters are used:

$$
\begin{gathered}
\operatorname{Re}=\frac{\rho U_{\infty}^{2-n} L^{n}}{m}, \quad x=\frac{X}{L}, \quad y=\frac{Y}{L} \operatorname{Re}^{1 /(n+1)}, \\
u=\frac{U}{U_{\infty}}, \quad v=\frac{V}{U_{\infty}} \operatorname{Re}^{1 /(n+1)},
\end{gathered}
$$

where $L$ is the plate length, $U_{\infty}$ is the far field velocity, and $\operatorname{Re}$ is generalized Reynolds number.

Combining (8), (10), and (11), the dimensionless momentum equation can be obtained:

$$
u \frac{\partial u}{\partial x}+v \frac{\partial u}{\partial y}=\frac{\partial}{\partial y}\left(\left|\frac{\partial u}{\partial y}\right|^{n-1} \frac{\partial u}{\partial y}\right)
$$

with the boundary conditions

$$
u(x, 0)=v(x, 0)=0, \quad u(x, \infty)=1, \quad u(0, y)=1 .
$$

Similarity variable and stream function for the problem is defined as [45]

$$
\begin{gathered}
\eta=\frac{y}{(n(n+1) x)^{1 /(n+1)}} \\
\Psi=(n(n+1) x)^{1 /(n+1)} f(\eta) .
\end{gathered}
$$

Regarding (14), the velocities can be obtained as a function of the similarity variable:

$$
\begin{gathered}
u=\frac{\partial \Psi}{\partial y}=f^{\prime}(\eta) \\
v=-\frac{\partial \Psi}{\partial x}=\frac{1}{n+1}\left[\frac{n(n+1)}{x^{n}}\right]^{1 /(n+1)}\left(\eta f^{\prime}(\eta)-f(\eta)\right) .
\end{gathered}
$$

Substituting (15) in (12), we have

$$
\left(\left|f^{\prime \prime}\right|^{n-1} f^{\prime \prime}\right)^{\prime}+n f f^{\prime \prime}=0
$$

Equation (16) is the boundary layer equation of the power-law fluid as a function of index $n$. For pseudoplastic fluid $(n<1)$ the value of the $f^{\prime \prime}(\eta)$ is more than zero [43, 45-48]. So, (16) can be simplified as

$$
\begin{aligned}
& f^{\prime \prime \prime}(\eta)+f(\eta)\left(f^{\prime \prime}(\eta)\right)^{2-n}=0 \quad \text { for } n \leq 1, \\
& f(0)=0, \quad f^{\prime}(0)=0, \quad f^{\prime}(\infty)=1 .
\end{aligned}
$$

\section{Solution of the Problem}

In this section, we try to solve (17) using DTM and multistep DTM. The solution consists of two stages; first through mathematical relations and applying DTM, the value of $f^{\prime \prime}(0)$ is found. After that, boundary layer equation of the pseudoplastic fluid is solved as an initial value problem (IVP) using multi-step DTM.
4.1. Applying DTM (Obtaining $\left.f^{\prime \prime}(0)\right)$. The BVP (17) can be transformed to an initial value problem with the replacement of the unknown initial condition $f^{\prime \prime}(0)=\lambda$ instead of the boundary condition at infinity $f^{\prime}(\infty)=1$ :

$$
\begin{gathered}
f^{\prime \prime \prime}(\eta)+f(\eta) s(\eta)=0 \quad \text { for } n \leq 1 \\
f(0)=0, \quad f^{\prime}(0)=0, \quad f^{\prime \prime}(0)=\lambda,
\end{gathered}
$$

where

$$
s(\eta)=\left(f^{\prime \prime}(\eta)\right)^{2-n} .
$$

By applying the DTM on (18) at $\eta=0$, the recursive relation is derived:

$$
\begin{gathered}
F(k+3)=\frac{-1}{(k+1)(k+2)(k+3)} \sum_{r=0}^{k} F(r) S(k-r) \\
F(0)=0, \quad F(1)=0, \quad F(2)=\frac{\lambda}{2} .
\end{gathered}
$$

Regarding (19),

$$
s^{\prime}(\eta) f^{\prime \prime}(\eta)=(2-n) f^{\prime \prime \prime}(\eta) s(\eta) .
$$

Taking differential transform on (21), we have

$$
\begin{aligned}
& \sum_{r=0}^{k}(r+1) S(r+1)(k-r+1)(k-r+2) F(k-r+2) \\
& \quad=(2-n) \sum_{r=0}^{k}(r+1)(r+2)(r+3) F(r+3) S(k-r) .
\end{aligned}
$$

From (19), the value of $S(0)$ can be obtained:

$$
S(0)=s(0)=\left(f^{\prime \prime}(0)\right)^{2-n}=\lambda^{2-n}
$$

Combining (20), (22), and (23), the coefficients of the Taylor series solution of (18) can be calculated:

$$
\begin{aligned}
& F(0)=0, \quad F(1)=0, \quad F(2)=\frac{\lambda}{2}, \\
& F(3)=0, \quad F(4)=0, \quad F(5)=\frac{-1}{120} \lambda^{3-n}, \\
& F(6)=0, \quad F(7)=0, \\
& F(8)=\frac{1}{1920} \lambda^{5-2 n}-\frac{1}{4032} \lambda^{5-2 n} n, \\
& F(9)=0, \quad F(10)=0, \\
& F(11)=\frac{-89}{1900800} \lambda^{7-3 n}+\frac{1027}{19958400} \lambda^{7-3 n} n-\frac{1}{71280} \lambda^{7-3 n} n^{2},
\end{aligned}
$$


Now, consider a similar equation (18) in which $\lambda=1$ :

$$
\begin{array}{ll}
g^{\prime \prime \prime}(\eta)+g(\eta)\left(g^{\prime \prime}(\eta)\right)^{2-n}=0 & \text { for } n \leq 1 \\
g(0)=0, & g^{\prime}(0)=0, \quad g^{\prime \prime}(0)=1 .
\end{array}
$$

In the same manner, the coefficients $G(k)$ are

$$
\begin{aligned}
& G(0)=0, \quad G(1)=0, \quad G(2)=\frac{1}{2}, \\
& G(3)=0, \quad G(4)=0, \quad G(5)=\frac{-1}{120}, \\
& G(6)=0, \quad G(7)=0, \quad G(8)=\frac{1}{1920}-\frac{1}{4032} n, \\
& G(9)=0, \quad G(10)=0, \\
& G(11)=\frac{-89}{1900800}+\frac{1027}{19958400} n-\frac{1}{71280} n^{2}, \\
& \vdots
\end{aligned}
$$

Substituting (24) and (26) in (2), the $f(\eta)$ and $g(\eta)$ are obtained. These functions have a relation as follows:

$$
f(\eta)=\lambda^{q} g\left(\lambda^{p} \eta\right), \quad p=\frac{2-n}{3}, q=\frac{2 n-1}{3} .
$$

For $n=1$, both values of $p$ and qare $1 / 3$ for the Blasius equation. From (27), we have

$$
f^{\prime}(\eta)=\lambda^{q+p} g^{\prime}\left(\lambda^{p} \eta\right) \longrightarrow f^{\prime}(\infty)=\lambda^{q+p} g^{\prime}(\infty) \text {. }
$$

Regarding (28) and the boundary condition at infinity in (17), the value of $\lambda$ can be obtained:

$$
\lambda=\left(\frac{1}{g^{\prime}(\infty)}\right)^{3 /(1+n)} .
$$

4.2. Applying Multi-Step DTM (Solution of IVPs). As was noted, multi-step DTM usually is used for solving problems in which Taylor series is diverged in the solution domain. This technique was already used to solve engineering and computational problems [49-57].

To solve boundary layer problems, the domain $[0, \infty)$ is replaced by $\left[0, \eta_{\infty}\right)$. But $\eta_{\infty}$ should be great enough that the solution is not to be dependent on. The solution domain should be divided to $N$ equal parts $\left(H=\eta_{\infty} / N\right)$. So, we have

$$
\begin{gathered}
g_{i}^{\prime \prime \prime}\left(\eta_{i}\right)+g_{i}\left(\eta_{i}\right) s_{i}\left(\eta_{i}\right)=0, \\
(i-1) H \leq \eta_{i}<i H, \quad \text { for } 1 \leq i \leq N,
\end{gathered}
$$

where

$$
s_{i}(\eta)=\left(g_{i}^{\prime \prime}(\eta)\right)^{2-n} .
$$

Applying multi-step DTM on (30) and (31), we have

$$
\begin{array}{r}
G_{i}(k+3)=\frac{-H^{3}}{(k+1)(k+2)(k+3)} \sum_{r=0}^{k} G_{i}(r) S_{i}(k-r), \\
\text { for } 1 \leq i \leq N
\end{array}
$$

$$
\begin{aligned}
& \sum_{r=0}^{k} \frac{(r+1)}{H} S_{i}(r+1) \frac{(k-r+1)(k-r+2)}{H^{2}} G_{i}(k-r+2) \\
& \quad=(2-n) \sum_{r=0}^{k} \frac{(r+1)(r+2)(r+3)}{H^{3}} G_{i}(r+3) S_{i}(k-r),
\end{aligned}
$$

for $1 \leq i \leq N$.

So

$$
S_{i}(1)=\frac{2-n}{G_{i}(2)}\left[3 G_{i}(3) S_{i}(0)\right] .
$$

And for $k \geq 1$

$$
\begin{aligned}
& S_{i}(k+1) \\
& =\frac{1}{2(k+1) G_{i}(2)}\left[-\sum_{r=0}^{k-1}(r+1) S_{i}(r+1)(k-r+1)\right. \\
& \times(k-r+2) G_{i}(k-r+2) \\
& +(2-n) \sum_{r=0}^{k}(r+1)(r+2)(r+3) G_{i} \\
& \left.\times(r+3) S_{i}(k-r)\right] .
\end{aligned}
$$

The initial conditions of the problem are considered for first sub domain ( $i=1$ ). Regarding (6), (25), and (31), initial conditions transformed as follows:

$$
\begin{gathered}
G_{1}(0)=g_{1}(0)=0 \\
G_{1}(1)=H g_{1}^{\prime}(0)=0 \\
G_{1}(2)=\frac{H^{2}}{2} g_{1}^{\prime \prime}(0)=\frac{H^{2}}{2} \\
S_{1}(0)=s_{1}(0)=\left(g_{1}^{\prime \prime}(0)\right)^{2-n}=1 .
\end{gathered}
$$

The boundary conditions of each sub domain are the continuity of the $g\left(\eta_{i}\right), g^{\prime}\left(\eta_{i}\right)$, and $g^{\prime \prime}\left(\eta_{i}\right)$. These boundary conditions can be obtained from (7):

$$
g_{i}\left(\eta_{i+1}\right)=\sum_{k=0}^{m} G_{i}(k)
$$

$$
g_{i+1}\left(\eta_{i+1}\right)=G_{i+1}(0)
$$

$$
\longrightarrow G_{i+1}(0)=\sum_{k=0}^{m} G_{i}(k)
$$


TABLE 2: Comparison of the DTM results, numerical solution, and results of Lemieux et al. [43].

\begin{tabular}{lccc}
\hline & $\begin{array}{c}\text { DTM } \\
f^{\prime \prime}(0)\end{array}$ & $\begin{array}{c}\text { Numerical } \\
f^{\prime \prime}(0)\end{array}$ & $\begin{array}{c}\text { Lemieux et al. [43] } \\
f^{\prime \prime}(0)\end{array}$ \\
\hline$n=0.1$ & 0.1091 & 0.1140 & 0.1085 \\
$n=0.2$ & 0.1472 & 0.1493 & 0.1470 \\
$n=0.3$ & 0.1881 & 0.1889 & 0.1882 \\
$n=0.4$ & 0.2306 & 0.2308 & 0.2307 \\
$n=0.5$ & 0.2734 & 0.2734 & 0.2734 \\
$n=0.6$ & 0.3156 & 0.3157 & 0.3156 \\
$n=0.7$ & 0.3567 & 0.3567 & 0.3567 \\
$n=0.8$ & 0.3962 & 0.3962 & 0.3962 \\
$n=0.9$ & 0.4339 & 0.4339 & 0.4339 \\
$n=1$ & 0.4696 & 0.4696 & 0.4696 \\
\hline
\end{tabular}

$$
\begin{aligned}
g_{i}^{\prime}\left(\eta_{i+1}\right) & =\sum_{k=1}^{m} \frac{k}{H} G_{i}(k) \\
g_{i+1}^{\prime}\left(\eta_{i+1}\right) & =\frac{G_{i+1}(1)}{H} \\
& \longrightarrow G_{i+1}(1)=\sum_{k=1}^{m} k G_{i}(k) \\
g_{i}^{\prime \prime}\left(\eta_{i+1}\right) & =\sum_{k=2}^{m} \frac{k(k-1)}{H^{2}} G_{i}(k) \\
g_{i+1}^{\prime \prime}\left(\eta_{i+1}\right) & =\frac{2}{H^{2}} G_{i+1}(2) \\
& \longrightarrow G_{i+1}(2)=\frac{1}{2} \sum_{k=2}^{m} k(k-1) G_{i}(k) .
\end{aligned}
$$

And we have for $S$

$$
\begin{aligned}
S_{i+1}(0) & =s_{i+1}\left(\eta_{i+1}\right)=\left(g_{i+1}^{\prime \prime}\left(\eta_{i+1}\right)\right)^{2-n} \\
& =\left(\sum_{k=2}^{m} \frac{k(k-1)}{H^{2}} G_{i}(k)\right)^{2-n} .
\end{aligned}
$$

The value of the $g^{\prime}\left(\eta_{\infty}\right)$ can be calculated by differentiating from (7):

$$
g^{\prime}(\infty) \simeq g^{\prime}\left(\eta_{\infty}\right)=g_{N}^{\prime}\left(\eta_{N+1}\right)=\sum_{k=1}^{m} \frac{k}{H} G_{N}(k) .
$$

The unknown parameter $(\lambda)$ is calculated from (29). Now, (18) is solved with a similar process like (25) using multi-step DTM. The only difference is that the condition $f^{\prime \prime}(0)=\lambda$ is replaced by the condition $g^{\prime \prime}(0)=1$.

In Figure $1 f^{\prime}(\eta)$ is illustrated for different values of $n$ and compared with the numerical solution and results of Lemieux et al. [43]. The numerical solution of the problem is done by the MATLAB software. Figures 2 and 3 show the variation of $f(\eta)$ and $f^{\prime \prime}(\eta)$, respectively. The most important step of this scheme is to choose the appreciate finite value of $\eta_{\infty}$. Thus to estimate this value, we start with an initial guess for $\eta_{\infty}$

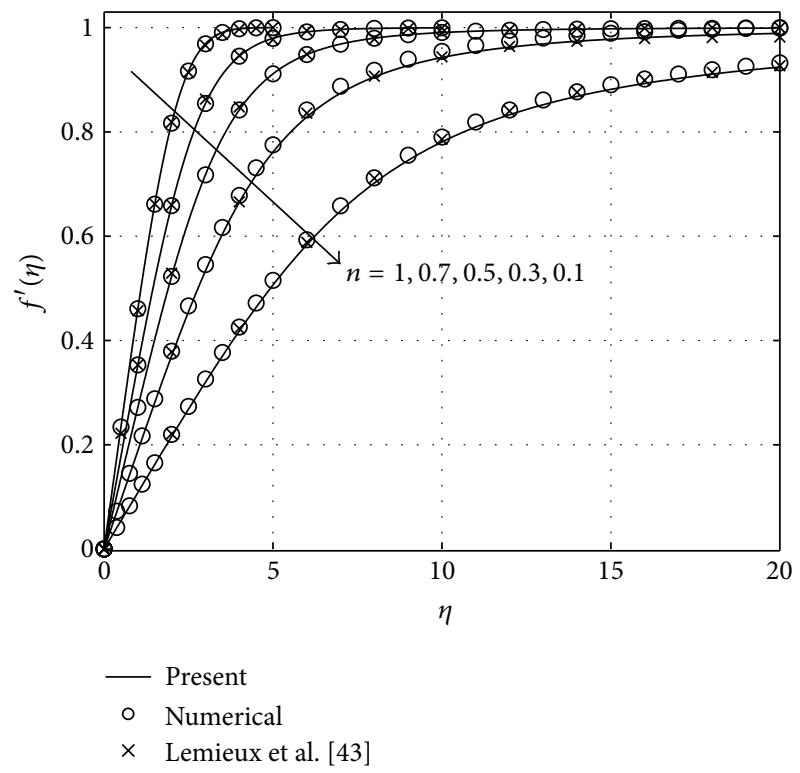

FIGURE 1: Variation of $f^{\prime}(\eta)$ and comparison with the numerical solution and results of Lemieux et al. [43].

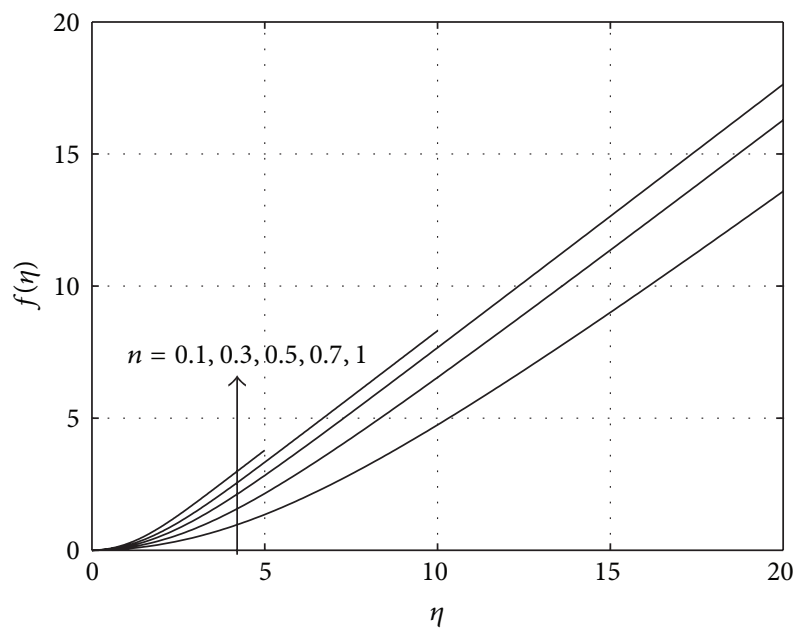

Figure 2: Variation of $f(\eta)$ for different values of $n$.

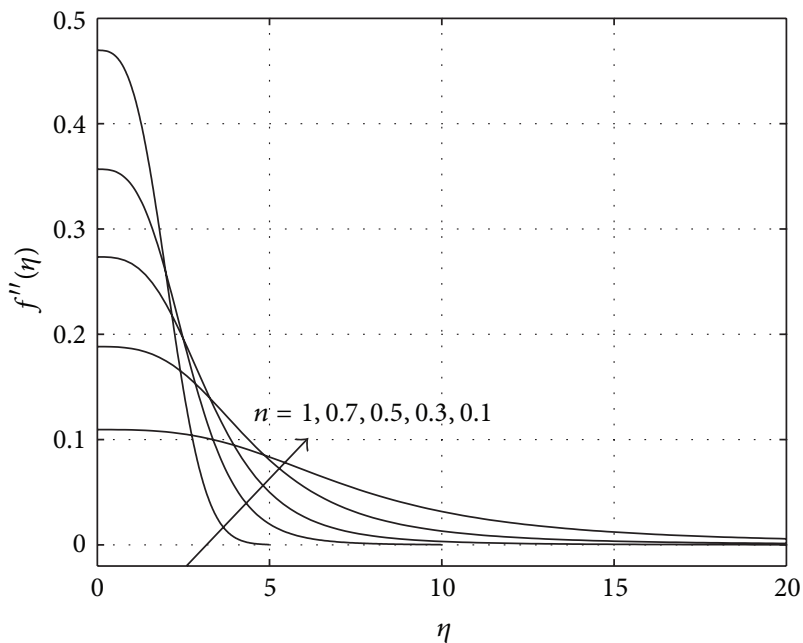

FIgURE 3: Variation of $f^{\prime \prime}(\eta)$ for different values of $n$. 
TABLE 3: The solution of $f(\eta)$ for $n=0.7$ when $\eta_{\infty}=10$ and $N=10$.

\begin{tabular}{lc}
\hline & Approximate solution \\
\hline $0 \leq \eta<1$ & $f(\eta)=0.1793 \eta^{2}-0.0008 \eta^{5}+0.0000 \eta^{8}+\cdots$, \\
$1 \leq \eta<2$ & $f(\eta)=0.1784+0.3546(\eta-1)+0.1716(\eta-1)^{2}-0.0074(\eta-1)^{3}-0.0033(\eta-1)^{4}+\cdots$, \\
$2 \leq \eta<3$ & $f(\eta)=0.6937+0.6617(\eta-2)+0.1290(\eta-2)^{2}-0.0197(\eta-2)^{3}-0.0018(\eta-2)^{4}+\cdots$, \\
$3 \leq \eta<4$ & $f(\eta)=1.4637+0.8577(\eta-3)+0.0679(\eta-3)^{2}-0.0182(\eta-3)^{3}-0.0021(\eta-3)^{4}+\cdots$, \\
$4 \leq \eta<5$ & $f(\eta)=2.3733+0.9481(\eta-4)+0.0272(\eta-4)^{2}-0.0090(\eta-4)^{3}-0.0020(\eta-4)^{4}+\cdots$, \\
$5 \leq \eta<6$ & $f(\eta)=3.3416+0.9824(\eta-5)+0.0098(\eta-5)^{2}-0.0033(\eta-5)^{3}+0.0009(\eta-5)^{4}+\cdots$, \\
$6 \leq \eta<7$ & $f(\eta)=4.3312+0.9948(\eta-6)+0.0036(\eta-6)^{2}-0.0012(\eta-6)^{3}+0.0003(\eta-6)^{4}+\cdots$, \\
$7 \leq \eta<8$ & $f(\eta)=5.3286+0.9993(\eta-7)+0.0014(\eta-7)^{2}-0.0004(\eta-7)^{3}+0.0001(\eta-7)^{4}+\cdots$, \\
$8 \leq \eta<9$ & $f(\eta)=6.2390+1.0012(\eta-8)+0.0006(\eta-8)^{2}-0.0002(\eta-8)^{3}+0.0000(\eta-8)^{4}+\cdots$, \\
$9 \leq \eta \leq 10$ & $f(\eta)=7.3307+1.0020(\eta-9)+0.0003(\eta-9)^{2}-0.0001(\eta-9)^{3}+0.0000(\eta-9)^{4}+\cdots$,
\end{tabular}

and solve the problem. The solution process is repeated with another larger value of $\eta_{\infty}$ until the values of $f^{\prime \prime}(0)$ and $g^{\prime \prime}(0)$ differ regarding the desired accuracy.

In Table 2 the values of the $f^{\prime \prime}(0)=\lambda$ are compared with the numerical solution and results of Lemieux et al. [43]. The approximate solution of the problem is presented in Table 3 for a special case $(n=0.7)$.

\section{Conclusion}

In this paper, the boundary layer equation of the pseudoplastic fluid over a flat plate was extracted from the boundary layer theory as presented in [43]. This equation is a boundary value problem with high nonlinearity and boundary condition at infinity. Using DTM, the BVP transformed to a pair of initial value problems and multi-step DTM is used to solve them.

Using the method, the differential equation and boundary conditions are transformed into a recurrence set of equations. Finally, the coefficients of power series are obtained based on the solution of this set of equations. The results validated with the numerical solution, and a good accuracy is observed. The proposed method overcame nonlinearity without using linearization or restrictive assumptions.

\section{References}

[1] S.-J. Liao, "A general approach to get series solution of nonsimilarity boundary-layer flows," Communications in Nonlinear Science and Numerical Simulation, vol. 14, no. 5, pp. 2144-2159, 2009.

[2] A. R. Ghotbi, H. Bararnia, G. Domairry, and A. Barari, "Investigation of a powerful analytical method into natural convection boundary layer flow," Communications in Nonlinear Science and Numerical Simulation, vol. 14, no. 5, pp. 2222-2228, 2009.

[3] Z. Ziabakhsh and G. Domairry, "Analytic solution of natural convection flow of a non-Newtonian fluid between two vertical flat plates using homotopy analysis method," Communications in Nonlinear Science and Numerical Simulation, vol. 14, no. 5, pp. 1868-1880, 2009.

[4] S. Abbasbandy and T. Hayat, "Solution of the MHD FalknerSkan flow by homotopy analysis method," Communications in Nonlinear Science and Numerical Simulation, vol. 14, no. 9-10, pp. 3591-3598, 2009.
[5] J. Cheng, S. Liao, R. N. Mohapatra, and K. Vajravelu, "Series solutions of nano boundary layer flows by means of the homotopy analysis method," Journal of Mathematical Analysis and Applications, vol. 343, no. 1, pp. 233-245, 2008.

[6] S.-J. Liao and I. Pop, "Explicit analytic solution for similarity boundary layer equations," International Journal of Heat and Mass Transfer, vol. 47, no. 1, pp. 75-85, 2004.

[7] S. Liao, "A new branch of solutions of boundary-layer flows over an impermeable stretched plate," International Journal of Heat and Mass Transfer, vol. 48, no. 12, pp. 2529-2539, 2005.

[8] T. Hayat and M. Sajid, "Homotopy analysis of MHD boundary layer flow of an upper-convected Maxwell fluid," International Journal of Engineering Science, vol. 45, no. 2-8, pp. 393-401, 2007.

[9] A. R. Ghotbi, "Homotopy analysis method for solving the MHD flow over a non-linear stretching sheet," Communications in Nonlinear Science and Numerical Simulation, vol. 14, no. 6, pp. 2653-2663, 2009.

[10] B. Raftari and A. Yildirim, "The application of homotopy perturbation method for MHD flows of UCM fluids above porous stretching sheets," Computers and Mathematics with Applications, vol. 59, no. 10, pp. 3328-3337, 2010.

[11] M. Esmaeilpour and D. D. Ganji, "Application of He's homotopy perturbation method to boundary layer flow and convection heat transfer over a flat plate," Physics Letters A, vol. 372, no. 1, pp. 33-38, 2007.

[12] L. Xu, "He's homotopy perturbation method for a boundary layer equation in unbounded domain," Computers and Mathematics with Applications, vol. 54, no. 7-8, pp. 1067-1070, 2007.

[13] M. Fathizadeh and F. Rashidi, "Boundary layer convective heat transfer with pressure gradient using Homotopy Perturbation Method (HPM) over a flat plate," Chaos, Solitons and Fractals, vol. 42, no. 4, pp. 2413-2419, 2009.

[14] H. Bararnia, E. Ghasemi, S. Soleimani, A. R. Ghotbi, and D. D. Ganji, "Solution of the Falkner-Skan wedge flow by HPM-Pade" method," Advances in Engineering Software, vol. 43, no. 1, pp. 44-52, 2012.

[15] H. Mirgolbabaei, D. D. Ganji, M. M. Etghani, and A. Sobati, "Adapted variational iteration method and axisymmetric flow over a stretching sheet," World Journal of Modelling and Simulation, vol. 5, no. 4, pp. 307-314, 2009.

[16] S. T. Mohyud-Din, A. Yildirim, S. Anl Sezer, and M. Usman, "Modified variational iteration method for free-convective boundary-layer equation using padé approximation," Mathematical Problems in Engineering, vol. 2010, Article ID 318298, 11 pages, 2010. 
[17] A.-M. Wazwaz, "The variational iteration method for solving two forms of Blasius equation on a half-infinite domain," Applied Mathematics and Computation, vol. 188, no. 1, pp. 485491, 2007.

[18] A.-M. Wazwaz, "The modified decomposition method and Padé approximants for a boundary layer equation in unbounded domain," Applied Mathematics and Computation, vol. 177, no. 2, pp. 737-744, 2006.

[19] E. Alizadeh, K. Sedighi, M. Farhadi, and H. R. Ebrahimi-Kebria, "Analytical approximate solution of the cooling problem by Adomian decomposition method," Communications in Nonlinear Science and Numerical Simulation, vol. 14, no. 2, pp. 462-472, 2009.

[20] S. A. Kechil and I. Hashim, "Non-perturbative solution of freeconvective boundary-layer equation by Adomian decomposition method," Physics Letters A, vol. 363, no. 1-2, pp. 110-114, 2007.

[21] E. Alizadeh, M. Farhadi, K. Sedighi, H. R. Ebrahimi-Kebria, and A. Ghafourian, "Solution of the Falkner-Skan equation for wedge by Adomian Decomposition Method," Communications in Nonlinear Science and Numerical Simulation, vol. 14, no. 3, pp. 724-733, 2009.

[22] J. K. Zhou, Differential Transformation and Its Applications for Electrical CircuIts, Huazhong University Press, Wuhan, China, 1986, (Chinese).

[23] F. Ayaz, "Applications of differential transform method to differential-algebraic equations," Applied Mathematics and Computation, vol. 152, no. 3, pp. 649-657, 2004.

[24] H. Liu and Y. Song, "Differential transform method applied to high index differential-algebraic equations," Applied Mathematics and Computation, vol. 184, no. 2, pp. 748-753, 2007.

[25] F. Ayaz, "Solutions of the system of differential equations by differential transform method," Applied Mathematics and Computation, vol. 147, no. 2, pp. 547-567, 2004.

[26] A. S. V. Ravi Kanth and K. Aruna, "Differential transform method for solving linear and non-linear systems of partial differential equations," Physics Letters A, vol. 372, no. 46, pp. 6896-6898, 2008.

[27] F. Ayaz, "On the two-dimensional differential transform method," Applied Mathematics and Computation, vol. 143, no. 2-3, pp. 361-374, 2003.

[28] X. Yang, Y. Liu, and S. Bai, "A numerical solution of secondorder linear partial differential equations by differential transform," Applied Mathematics and Computation, vol. 173, no. 2, pp. 792-802, 2006.

[29] S.-H. Chang and I.-L. Chang, "A new algorithm for calculating two-dimensional differential transform of nonlinear functions," Applied Mathematics and Computation, vol. 215, no. 7, pp. 24862494, 2009.

[30] B. Jang, "Solving linear and nonlinear initial value problems by the projected differential transform method," Computer Physics Communications, vol. 181, no. 5, pp. 848-854, 2010.

[31] Z. M. Odibat, "Differential transform method for solving Volterra integral equation with separable kernels," Mathematical and Computer Modelling, vol. 48, no. 7-8, pp. 1144-1149, 2008.

[32] A. Arikoglu and I. Ozkol, "Solutions of integral and integrodifferential equation systems by using differential transform method," Computers and Mathematics with Applications, vol. 56, no. 9, pp. 2411-2417, 2008.

[33] A. Arikoglu and I. Ozkol, "Solution of boundary value problems for integro-differential equations by using differential transform method," Applied Mathematics and Computation, vol. 168, no. 2, pp. 1145-1158, 2005.

[34] C.-L. Chen and Y.-C. Liu, "Differential transformation technique for steady nonlinear heat conduction problems," Applied Mathematics and Computation, vol. 95, no. 2-3, pp. 155-164, 1998.

[35] S. Mosayebidorcheh and T. Mosayebidorcheh, "Series solution of convective radiative conduction equation of the nonlinear fin with temperature dependent thermal conductivity," In press.

[36] S.-U. Islam, S. Haq, and J. Ali, "Numerical solution of special 12th-order boundary value problems using differential transform method," Communications in Nonlinear Science and Numerical Simulation, vol. 14, no. 4, pp. 1132-1138, 2009.

[37] M. Torabi and A. Aziz, "Convective-radiative fins with simultaneous variation of thermal conductivity, heat transfer coefficient, and surface emissivity with temperature," Heat Transfer, vol. 41, no. 2, pp. 99-113, 2012.

[38] A. A. Joneidi, D. D. Ganji, and M. Babaelahi, "Differential Transformation Method to determine fin efficiency of convective straight fins with temperature dependent thermal conductivity," International Communications in Heat and Mass Transfer, vol. 36, no. 7, pp. 757-762, 2009.

[39] D. Nazari and S. Shahmorad, "Application of the fractional differential transform method to fractional-order integrodifferential equations with nonlocal boundary conditions," Journal of Computational and Applied Mathematics, vol. 234, no. 3, pp. 883-891, 2010.

[40] Z. Odibat, S. Momani, and V. S. Erturk, "Generalized differential transform method: application to differential equations of fractional order," Applied Mathematics and Computation, vol. 197, no. 2, pp. 467-477, 2008.

[41] V. S. Erturk, S. Momani, and Z. Odibat, "Application of generalized differential transform method to multi-order fractional differential equations," Communications in Nonlinear Science and Numerical Simulation, vol. 13, no. 8, pp. 1642-1654, 2008.

[42] A. Arikoglu and I. Ozkol, "Solution of fractional differential equations by using differential transform method," Chaos, Solitons and Fractals, vol. 34, no. 5, pp. 1473-1481, 2007.

[43] P. F. Lemieux, R. N. Dubey, and T. E. Unny, "Variational method for a pseudoplastic fluid in a laminar boundary layer over a flat plate," Journal of Applied Mechanics, Transactions ASME, pp. 345-349, 1971.

[44] G. A. Baker, Essentials of Pade Approximants, Academic Press, New York, NY, USA, 1975.

[45] T. G. Myers, "An approximate solution method for boundary layer flow of a power law fluid over a flat plate," International Journal of Heat and Mass Transfer, vol. 53, no. 11-12, pp. 23372346, 2010.

[46] M. Benlahsen, M. Guedda, and R. Kersner, "The Generalized Blasius equation revisited," Mathematical and Computer Modelling, vol. 47, no. 9-10, pp. 1063-1076, 2008.

[47] J. P. Denier and P. P. Dabrowski, "On the boundary-layer equations for power-law fluids," Proceedings of the Royal Society A, vol. 460, no. 2051, pp. 3143-3158, 2004.

[48] C.-C. Hsu, "A simple solution for boundary layer flow of power law fluids past a semi-infinite flat plate," AIChE Journal, vol. 15, no. 3, pp. 367-370, 1969.

[49] H. Yaghoobi and M. Torabi, “The application of differential transformation method to nonlinear equations arising in heat transfer," International Communications in Heat and Mass Transfer, vol. 38, no. 6, pp. 815-820, 2011. 
[50] M. M. Rashidi, A. J. Chamkha, and M. Keimanesh, "Application of multi-step differential transform method on flow of a secondgrade fluid over a stretching or shrinking sheet," American Journal of Computational Mathematics, vol. 6, pp. 119-128, 2011.

[51] M. Keimanesh, M. M. Rashidi, A. J. Chamkha, and R. Jafari, "Study of a third grade non-Newtonian fluid flow between two parallel plates using the multi-step differential transform method," Computers and Mathematics with Applications, vol. 62, no. 8, pp. 2871-2891, 2011.

[52] L.-T. Yu and C.-K. Chen, "The solution of the Blasius equation by the differential transformation method," Mathematical and Computer Modelling, vol. 28, no. 1, pp. 101-111, 1998.

[53] B.-L. Kuo, "Application of the differential transformation method to the solutions of Falkner-Skan wedge flow," Acta Mechanica, vol. 164, no. 3-4, pp. 161-174, 2003.

[54] Z. M. Odibat, C. Bertelle, M. A. Aziz-Alaoui, and G. H. E. Duchamp, "A multi-step differential transform method and application to non-chaotic or chaotic systems," Computers and Mathematics with Applications, vol. 59, no. 4, pp. 1462-1472, 2010.

[55] H.-S. Peng and C.-L. Chen, "Hybrid differential transformation and finite difference method to annular fin with temperaturedependent thermal conductivity," International Journal of Heat and Mass Transfer, vol. 54, no. 11-12, pp. 2427-2433, 2011.

[56] Y.-L. Yeh, C. C. Wang, and M.-J. Jang, "Using finite difference and differential transformation method to analyze of large deflections of orthotropic rectangular plate problem," Applied Mathematics and Computation, vol. 190, no. 2, pp. 1146-1156, 2007.

[57] H. P. Chu and L. Ch. Chen, "Hybrid differential transform and finite difference method to solve the nonlinear heat conduction problem," Communications in Nonlinear Science and Numerical Simulation, vol. 13, pp. 1605-1614, 2008. 


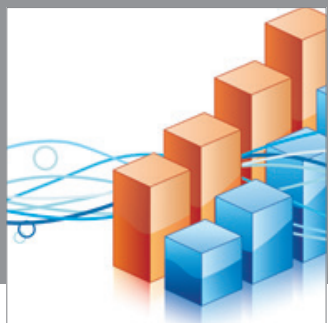

Advances in

Operations Research

mansans

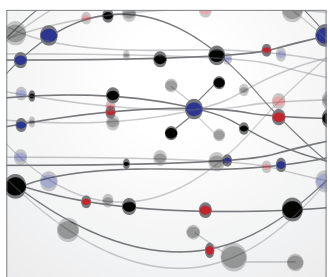

The Scientific World Journal
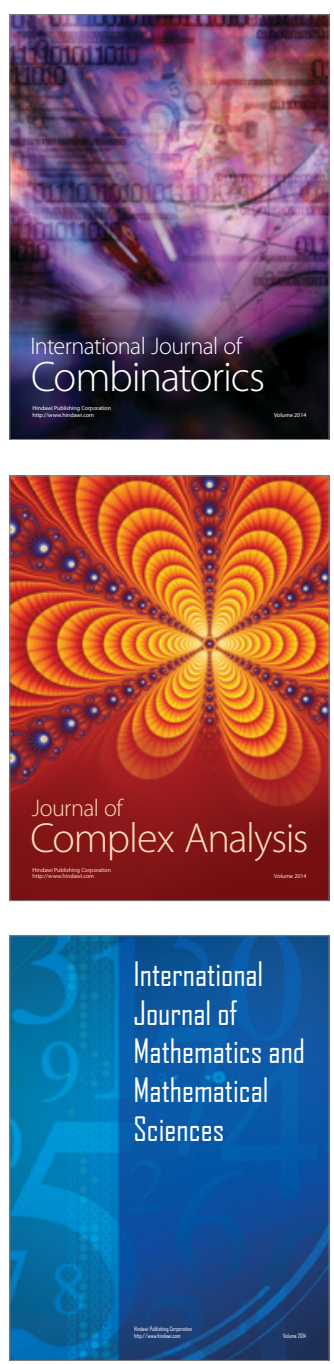
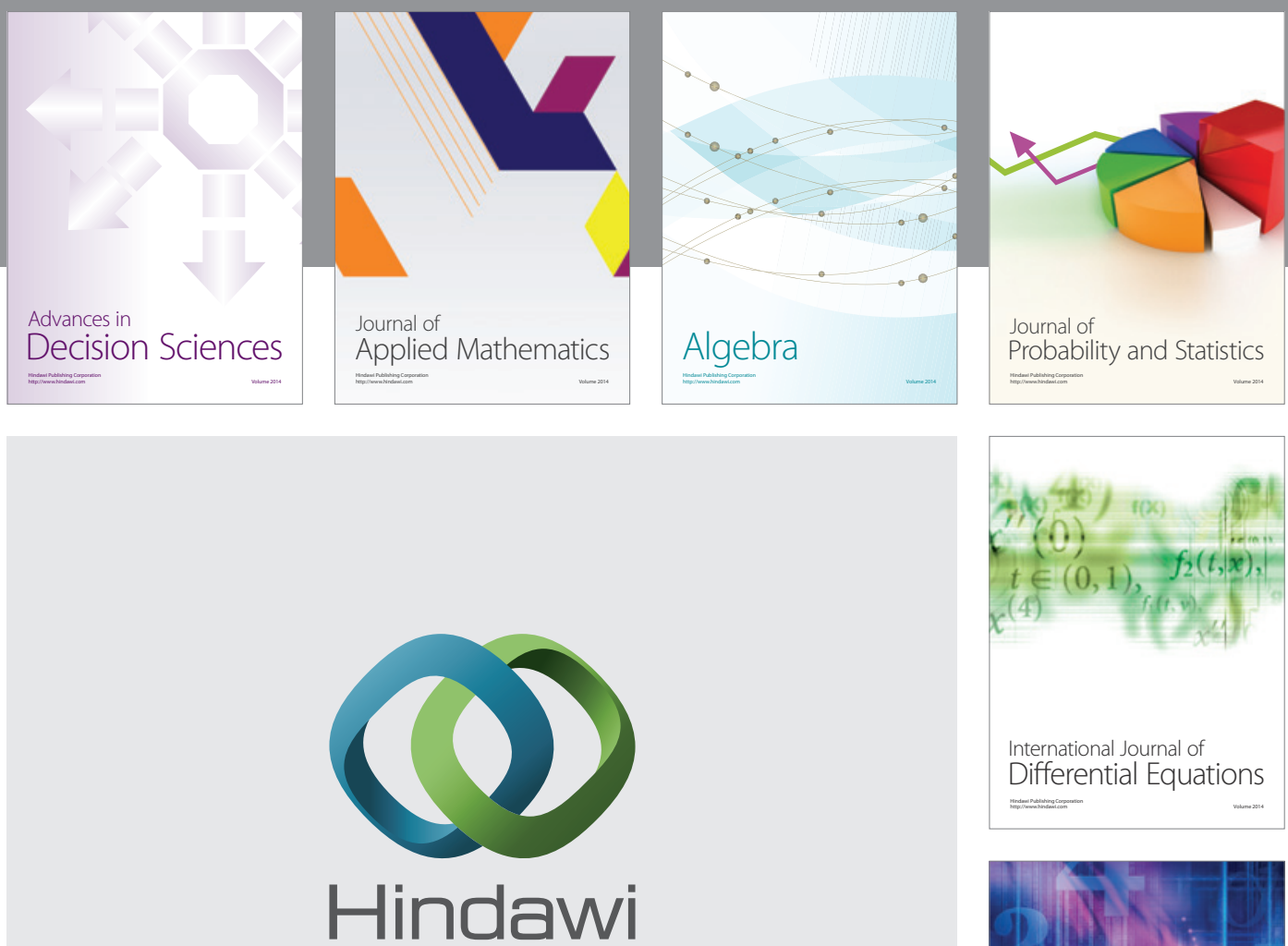

Submit your manuscripts at http://www.hindawi.com
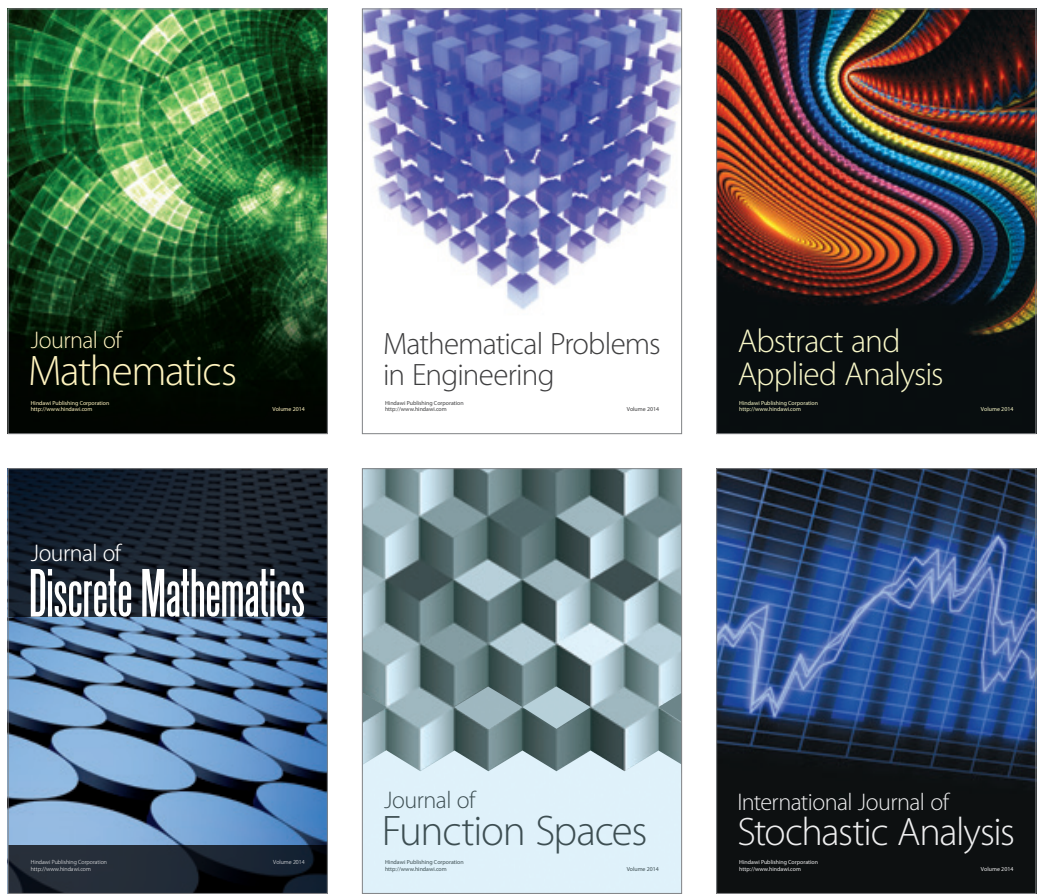

Journal of

Function Spaces

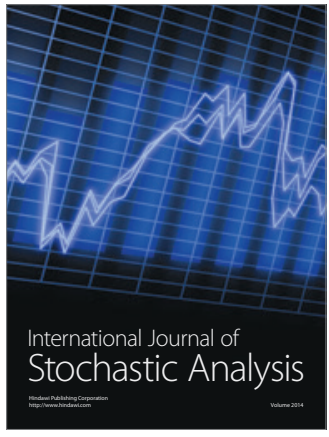

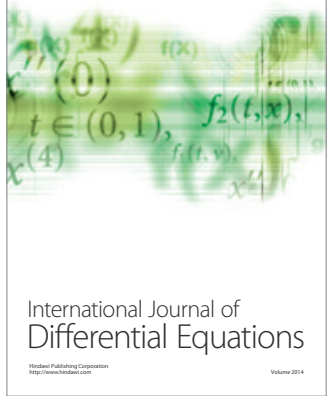
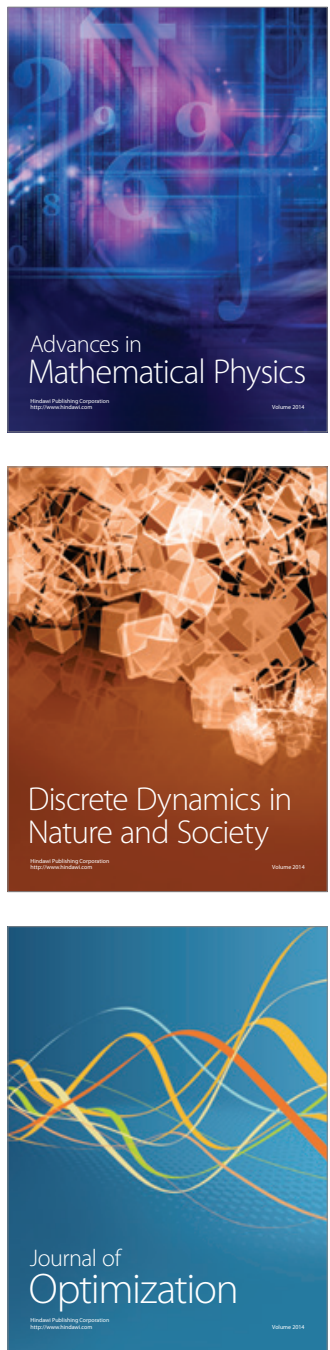